\title{
Emergency contraception: Idea to program
}

\author{
Saumya RamaRao \\ Population Council \\ John Townsend \\ Population Council \\ Sarah Raifman \\ Population Council
}

Follow this and additional works at: https://knowledgecommons.popcouncil.org/departments_sbsr-rh

Part of the Community-Based Research Commons, Gender and Sexuality Commons, International Public Health Commons, Maternal and Child Health Commons, Obstetrics and Gynecology Commons, Public Health Education and Promotion Commons, and the Women's Health Commons How does access to this work benefit you? Let us know!

\section{Recommended Citation}

RamaRao, Saumya, John Townsend, and Sarah Raifman. 2010. "Emergency contraception: Idea to program," brief. Washington, DC: Population Council. 


\section{Emergency Contraception: Idea to Program}

Saumya RamaRao, John W. Townsend, and Sarah Raifman

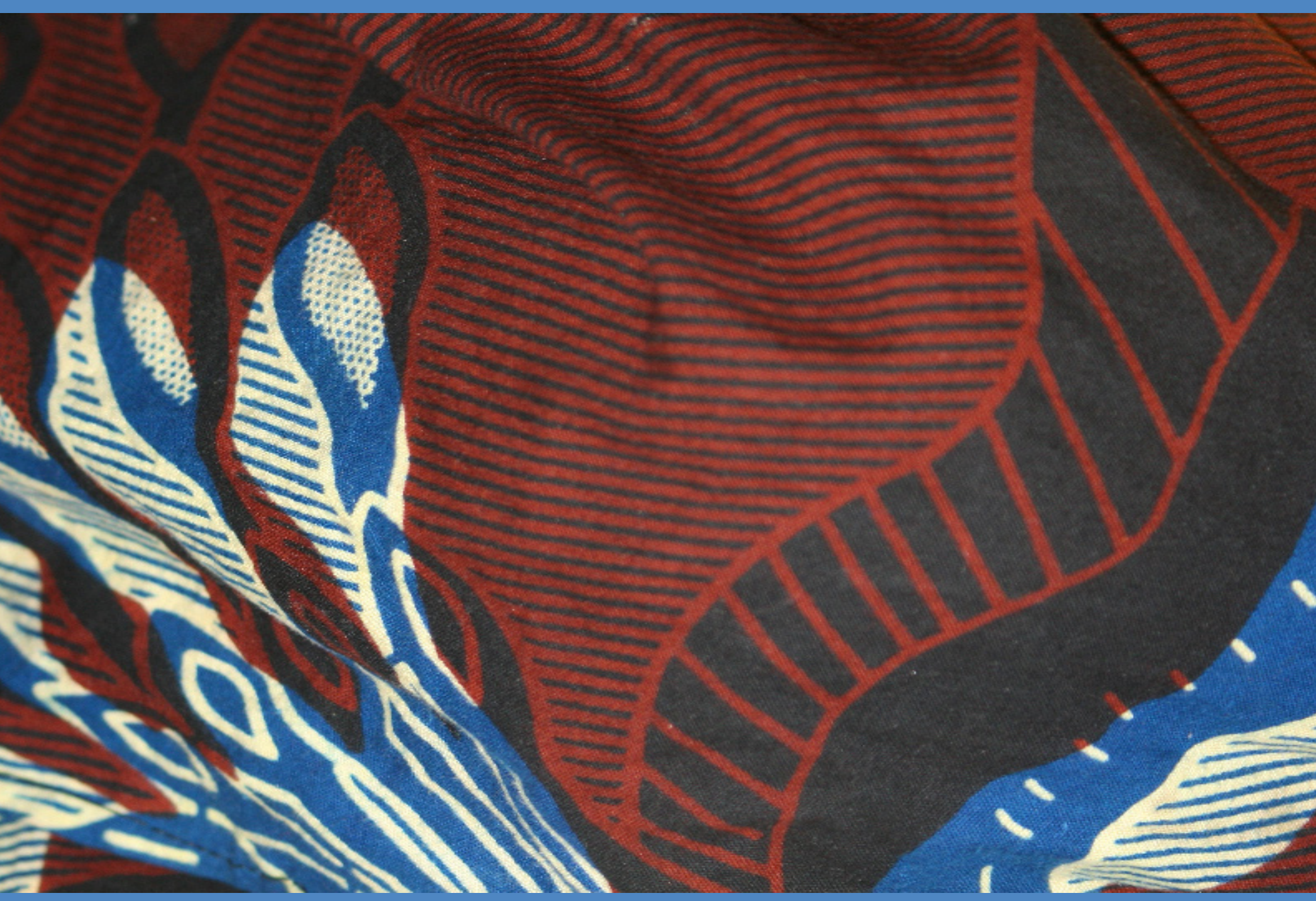


Tel: (202) 237-9400

\begin{abstract}
A Population Council
\end{abstract}

\title{
www.popcouncil.org \\ 4301 Connecticut Ave, NW
Suite 280 \\ 4301 Connecticut Ave, NW
Suite 280
}

(1)

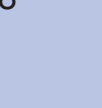

\author{
Washington, DC 20008
}

(n)

Tel: (202)

(

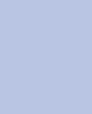

$\sqrt{2}$

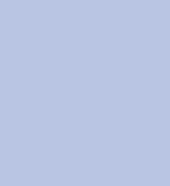

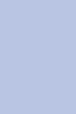

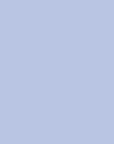

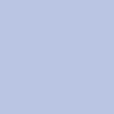

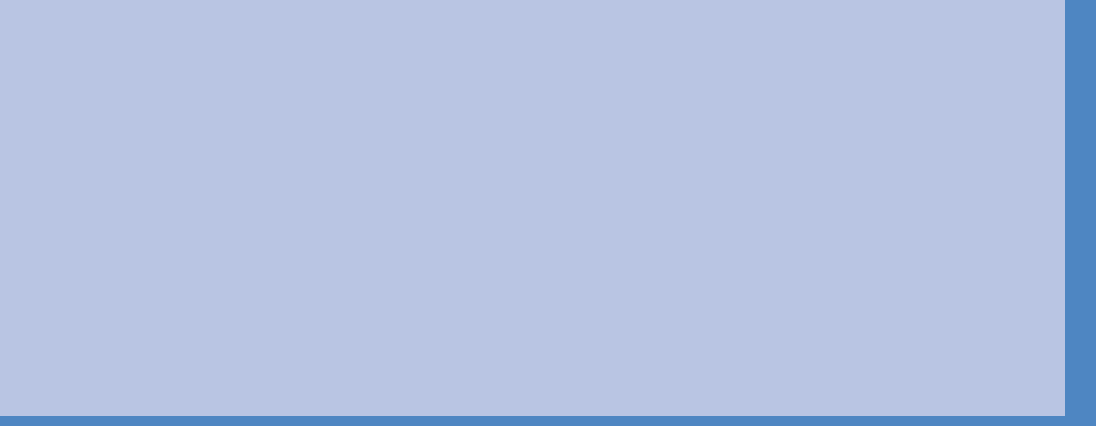

(1) (1)

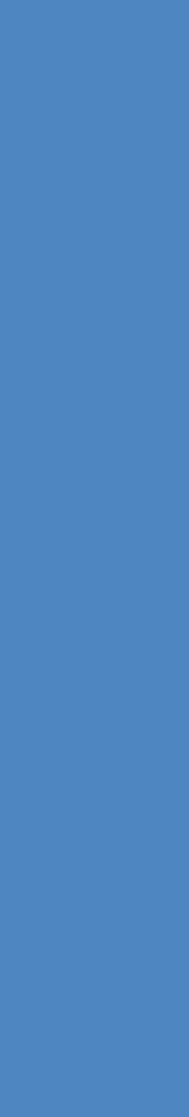




\section{Contents}

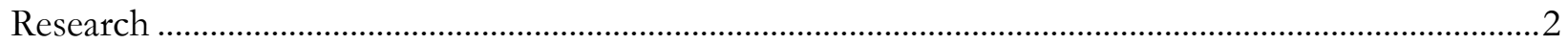

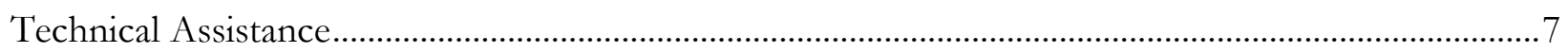

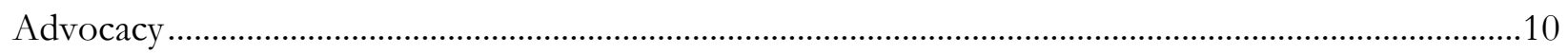

Working in Partnerships, Leveraging Funds and Resources ................................................................11

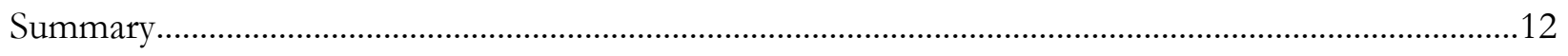

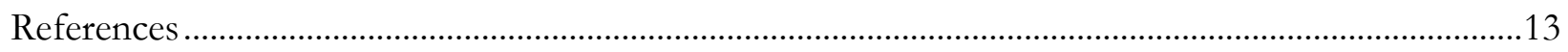




\section{Emergency Contraception: Idea to Program}

In the mid-1990s, emergency contraception was being discussed as an issue requiring advocacy, support, and additional research to bolster the case for introduction and subsequent scale-up (Ellertson et al., 1995). Evidence was gathered on the safety, efficacy and availability of emergency contraception (EC); rationales were developed on the grounds of human rights and equity; and calls were issued for clinical, behavioral and Operations Research in developing countries. In 1996, the International Consortium for Emergency Contraception (ICEC) was founded to play a role in introducing EC in a wide range of settings and share research and practice amongst important players.

Since that time, the Population Council has generated empirical evidence from a variety of developing country settings in Africa, South Asia, and Latin America to shed light on different aspects of the potential demand for emergency contraception and the provision of services. This report summarizes the role of the Population Council in generating evidence, providing technical leadership, and demonstrating at scale that EC can be easily integrated into national family planning programs and other RH services.

\section{Research}

The Council conducts both biomedical and social science research to design, test, and develop reproductive health technologies and service-delivery programs to improve the health of individuals in developing countries. With evidence from our research, Council staff provide technical support, inform decision makers about effective policies, and assist governments in implementing national programs. Council research is often conducted in collaboration with private health networks, governments, and nongovernmental organizations in developing countries.

\section{Bio-medical research}

Biomedical research has resulted in various combinations of compounds that can be used for emergency contraceptive pills. An early regimen was a combined ethinyl estradiol and levonorgestrel (LNG) hormonal contraceptive, called the Yuzpe regimen. However, fewer side-effects and higher efficacy were observed among users of the LNG-only regimen, making the LNG regimen (progestin-only pill) the method of choice. Subsequently, the use of LNG for EC increased; yet, despite its common use for EC, little was known about its pharmacokinetics and optimal dose. Council-supported research has demonstrated the pharmacokinetics for alternate dosing regimens of LNG which have had profound programmatic implications for optimal dosing and feasible administration of the drug (Johansson et al., 2002). Additional research provided evidence that the standard dose of LNG for emergency contraception could be reduced (and even halved) to achieve 
the same level of efficacy (Croxatto et al., 2004). Today, it is known that a single dose of $0.75 \mathrm{mg}$ of LNG could improve compliance while at the same time inhibiting ovulation.

\section{Provider knowledge, attitudes and practices}

In a number of countries, since the early 2000s, emergency contraceptive pills have been made available through a range of providers. Similar to the experience of other product and service introductions into the health system, efforts are required to develop service delivery models and messages, design training programs for providers, and prepare logistics and related support systems. The following are illustrations of the type and range of service-related issues examined.

Service providers_-nurses, midwives and pharmacists — are points of contact with potential users and are important intermediaries for family planning information transmission and service provision. Surveys of health care providers in Jamaica and Barbados indicated that while providers had heard of emergency contraceptive pills, they did not have comprehensive knowledge about the method; for example, about when to dispense the method, its safety features, and effectiveness (Yam et al., 2007).

In Senegal, researchers evaluated the availability and quality of EC services provided by private pharmacies. EC is well-suited to be dispensed via pharmacies; furthermore, it improves client access by increasing the number of sources through which supplies may be procured. The study also shed light on the type of care that pharmacies provide to potential clients. Not surprisingly, interaction between pharmacy providers and clients was not always considered good quality:

"The service providers don't take the time to speak with clients; they rarely speak and therefore their explanations are incomplete."

(ECafrique, Study on EC at the Pharmacy Level, 2009)

Perceptions of who uses EC and under what circumstances also seem to influence pharmacy providers in their dispensation of the method. Those who are completely opposed to EC justify their position by emphasizing that:

"The Muslim religion recommends that adolescents remain virgins until marriage."

(ECafrique, Study on EC at the Pharmacy Level, Senegal 2009)

Those providers in favor of EC perceive it as a way of regulating births in the case that women forgot contraception, or the contraception used did not work, but only for those women who are adults or married. Some providers are wary of abuse and recommend that:

"Adult women should understand that EC should not be taken each time. They should use family planning." (ECafrique, Study on EC at the Pharmacy Level, 2009)

Evidence, such as the above, has helped refine EC introduction strategies, prepare education materials, design training curriculums and address systemic health sector challenges. In Senegal, the Ministry of Health, with support from the Population Council/ECafrique, has trained service providers and community volunteers to offer EC; designed tools for service delivery and distributed 
them to health facilities; and developed IEC materials. Based on this study of private pharmacies, the Council is now assessing pharmacist-purchaser knowledge transfer to identify strategies to improve service delivery in pharmacies.

\section{User/Client knowledge, profile and use patterns}

Monitoring and evaluating the introduction and distribution of emergency contraception in developing countries is an important part of the Council's role in mainstreaming EC use. In order to ensure quality of service delivery as well as program efficacy, the Council is investigating client knowledge and use patterns of EC. Data gathered from family planning clinic users in Honduras confirmed that introduction of EC into the national family planning norms does not translate immediately or automatically into increased knowledge or use (García et al., 2006). Honduran and international NGOs launched a series of outreach activities in 2001 to bolster the 1999 introduction of EC into the $\mathrm{MOH}$ norms. Findings from the study were that, four years post EC introduction into the country, less than one in five family planning users knew about such a method. However, other findings suggest that clients hold favorable attitudes towards EC with low rates of reported concern about the method. The study provided critical and timely information to the Honduran $\mathrm{MOH}$ about the potential demand for the product and the need to tailor specific messages to subsegments of the population, such as youth and the less educated.

Studies in Ghana and Senegal on mainstreaming EC presented largely positive results on client usage. In Ghana, focus group participants and interviewees were asked to characterize the role of the EC pill. Responses indicated that the discussants generally viewed EC as a safety net:

"Someone you can count on," and "A close friend of sexually active young ladies."

(Mainstreaming EC in Africa: The EC Facilitative Re-granting Program. September, 2009)

In Senegal, clients supported using the method because:

"[EC] is a good way of giving women the opportunity to decide for themselves about their motherbood." (Study on EC at the Pharmacy Level, Senegal 2009)

Another client said:

"[EC] is good for loyal couples who have made a mistake or forgotten to calculate their period of fecundity." (Study on EC at the Pharmacy Level, Senegal 2009)

However, misconceptions also abounded. One female user remarked:

"It is a method that can be taken right before sex. I believe that it is a suppository."

(Population Council factsheet, "EC: Addressing Unwanted Pregnancies and Maternal Mortality in Senegal) 
Yet others were not in favor of the method and viewed the emergency contraceptive pill as a gateway to increased unprotected intercourse and irresponsibility. They argued that the method was against Islam, creating an unsupported link between practicing the method and sexual debauchery.

Evidence such as these have informed IEC campaigns and client education materials as well as contributed to a better understanding of community sensitivities.

\section{Operations Research on EC provision}

Assessing feasibility of service provision involves reviewing availability, access, and cost of the drug. A small intervention study in Mexico experimented with providing information on emergency contraceptive pills to factory workers at their worksite (Garcia et al., 2008). The results indicate that worksite programs can be a viable mechanism to provide information and some education within working hours. However, the extent to which such workplace programs can be implemented depends on the level of commitment of the factory owners, and their opposition or support of emergency contraception.

Access to emergency contraceptive pills in India increased when the Government of India changed the regulation from EC only being prescribed by a physician to being available over-the-counter. The change in policy occurred after a study comparing the services provided by physicians and paraprofessionals (auxiliary nurse midwives and lady health visitors) demonstrated that paraprofessionals provided higher levels of care while retaining the same amount of knowledge as physicians post training. Based on these findings, the Indian Ministry of Health and Family Welfare introduced EC as an over-the-counter medication in September 2005, making it possible for paraprofessionals, who are first-line health workers and closer to communities, to provide EC services, thereby increasing access overall(Kumar et al., 2007).

Timely access to EC can be a barrier to use. In some settings there have been concerns that prophylactic provision may result in overuse or misuse. These concerns have been allayed with evidence from Bangladesh where comparisons in EC uptake and use were made when EC was provided on-demand and prophylactically. Women living in the area where the EC service was available in advance were five times more likely to report use than women living in areas where it was only available after unprotected intercourse (Khan, Hossain, and Rahman 2004). ${ }^{1}$ Results indicated that prophylactic distribution did not result in overuse or misuse; on the other hand, even though EC was available on demand, women continued to face barriers to timely access (Khan and Hossain, 2008). Based on these data, the Bangladesh Director General of Family Planning has approved the provision of EC as a prophylactic measure.

\footnotetext{
${ }^{1}$ However, in one randomized trial in the U.S. considering the effect of advance EC provision on regular methods of birth control, teens receiving emergency contraception supplies in advance were more likely to use EC when needed but did not report higher frequencies of unprotected sex, did not use condoms or hormonal contraception less often, and did not exhibit higher rates of STIs (Trussell and Raymond, 2010).
} 


\section{Strategies for Integration of EC into existing RH services}

Integrating services is important to increase access to reproductive health care, particularly for those who are most vulnerable within the community, such as refugees or rape/assault victims. Integration is cost-efficient and effective, and will better allow for mainstreaming the distribution and delivery of services.

Integration into refugee settings: Women and girls fleeing volatile conflict situations and those at refugee camps are particularly in need of EC due to sexual violence they may have experienced. While there is broad agreement for the need for emergency post-coital contraception as a tool for managing the consequences of sexual violence, experience of providing these services in refugee settings is limited. With support from the Compton Foundation, the Council conducted a series of data collection and training activities in three refugee camps in Kenya managed by the International Rescue Committee (Muia et al., 2002; Muia et al., 2000). This intervention research demonstrated the need for standardized service guidelines, IEC materials and for creating a conducive service environment at both clinic and community sites. While the research highlighted the feasibility of training service providers, it also documented the challenges of incorporating EC services in routine service delivery and the barriers that refugees face in accessing services including misinformation about the method and services, and stigma.

Integrating EC into rape/assault services: The narrow window of opportunity to reduce the risk of a pregnancy after rape (120 hours) requires that EC information and services are provided at the first point of contact with a rape survivor, or as soon as possible afterwards.

In several countries (including Ecuador, Guatemala, Mexico, and Zambia), EC counseling and services were introduced in police precincts and in rape care centers.

In Zambia, the majority of rape survivors in the Copperbelt region go to the police before seeking healthcare (Keesbury and Zama 2007). Moreover, although considerable proportions of survivors reach a health facility within the time window for EC use, less than half receive EC from hospital staff. These results encouraged the Ministry of Health to train police officers as community-based EC distributors. Estimates suggest that enabling police to provide EC could benefit up to 59 percent of rape survivors, with little difference between rural and urban locations (Keesbury, Skibiak, and Zama 2006). Health sector staff was pleased with the intervention, noting:

'We haven't faced any challenges regarding these EC being administered by police officers. If any, it has made our job easier because by the time survivors come to the hospital, they already have received some help so we just pick. up where our friends left ended."

Reporting of sexual violence cases increased (by 48\%) in participating police stations from 2006 to 2007 , and the program was perceived by provincial management as successful, sustainable and costeffective. 
One official said:

"This program is resource cheap in the sense that it doesn't need a lot of funds to be sustained; keeping in mind that the most expensive part of sustainability of such programs is manpower which we partly have in an already existing system" (Keesbury and Zama, 2009).

In other settings where legal abortion is available under restrictive conditions, EC provides a feasible service delivery solution. In Mexico, legislation specifying the norms by which women can obtain a legal abortion is so complex and difficult to understand that it is difficult for women to choose abortion as a solution to unwanted pregnancies arising from rape or assault. Therefore, a partial solution is the immediate provision of emergency contraception to raped women.

Providing brochures on EC at the first point of contact rather than providing the method itself was used in Mexico because, in the absence of official guidelines, staff at public agencies were afraid they could be charged with providing abortions and providing drugs without a medical license (Vernon, Schiavon and Llaguno 1998). Psychologists of the Federal District's Attorney General Office were trained to provide information on emergency contraception to women who reported a rape and eleven medical back-up referral centers were established where EC could be obtained.

\section{Technical Assistance}

The Population Council provides technical assistance to support service-delivery, education, training, and monitoring and evaluation of reproductive health programs, such as the introduction of EC. Technical consultations and high level discussions are facilitative mechanisms for the sharing of state of the art technical knowledge, program experience, solutions for common challenges, and building an effective community of practice. The following illustrate the different ways that the Council has provided technical support for increasing access to EC, particularly assisting $\mathrm{MOH}$ to add EC to national FP guidelines and availability of method.

\section{Technical Assistance for scaling-up and mainstreaming}

After demonstration of a successful service delivery pilot approach, further technical assistance is required to apply the lessons and findings generated. Scale-up or mainstreaming into an existing program requires a different set of targeted activities and resources. For example, after the Council's FRONTIERS Program demonstrated the feasibility and accessibility of EC in Bangladesh (Khan, Hossain, and Rahman, 2004), the government made a policy decision to formally introduce EC in the national family planning program. The single-dose EC is now approved for distribution throughout the country (Khan and Hossain, 2008). In order to do this, the Council provided technical assistance over a four-year period in three key areas: a) building capacity of the national system to train its staff about EC provision and monitor implementation; b) implementing the EC program at a national level; and c) monitoring program implementation and undertaking special studies to document and modify the process of scale-up. Scale-up was conducted in a systematic and phased manner: EC was first introduced in the capital division of Dhaka (to 41 million people) 
and then in five other divisions (to 89 million people). A three tiered training program produced 297 master trainers, 2,264 trainers, and 44,774 providers of EC (Khan, Hossain, and Bhuiyan, 2005; Khan and Hossain, 2008).

A second significant success has been the inclusion of EC into Mexico's official National Family Planning Norms in January 2004. In 2005, EC dedicated products were added to Mexico's essential drug list. There are currently $5 \mathrm{EC}$ dedicated products available in Mexico. Abortion is highly restrictive across all 32 states, except for the Federal District (Mexico City). Beginning in late 2009, however, 17 states have passed legislation to further restrict abortion, including for rape resulting in pregnancy. The introduction of EC in Mexico took about a decade, which reflects the complexity of converting research results into public policy. In the lead up to this, Population Council carried out knowledge, attitudes and practice (KAP) surveys; conducted trainings for health care providers and users; and launched broad-based informational campaigns - including a dedicated EC website and a toll-free national hotline. With ample support of civil organizations, the demand for EC by the population, and the minister of health's support of EC, the Council was able to generate substantial evidence, advocate, and build networks to promote EC, which subsequently led to policy change in Mexico.

The Bangladesh experience of introducing and scaling-up EC has been a useful illustration for other neighboring South Asian countries interested in this service area. Study visits by officials of $\mathrm{MOH}$ Pakistan to Bangladesh provided opportunities for dialogue with Bangladeshi counterparts and give useful insights into introduction strategies. Subsequent to the study visit, in January 2008 a two-day consultative meeting was organized by MOPW, the $\mathrm{MOH}$ and the Council in Islamabad to discuss the introduction of EC in Pakistan's MOH. With information about the successes of India, Bangladesh, and Nepal, the $\mathrm{MOH}$ approved the introduction of $\mathrm{EC}$ in $\mathrm{MOH}$ clinics and a national policy change to incorporate EC in national FP program. EC is now provided in 20 districts of Pakistan.

Although EC was included in the Nepal National Medical Standards for Contraceptive Services and Clinical Protocol for Health Providers since 2003, they were available only in selected areas where Population Services International (PSI) provided social marketing of the products. In 2004, the Family Health Division (FHD) of the $\mathrm{MOH}$ hosted an EC consultation meeting for sharing of knowledge and experience of South Asian experiences of EC national introduction. The NGO, Centre for Research on Environment Health and Population Activities (CREHPA) presented evidence on the extent of unprotected intercourse and the need for EC in Nepal. As an outcome of this consultation, FHD adopted the model used in Bangladesh for EC introduction into the public sector family planning program along with the educational materials that had been designed and tested in India. The Population Council provided technical assistance and contributed to building national capacity in EC training of service providers. Process monitoring and documentation were included in the technical support (Shrestha, Hossain, and Khan, 2008). 
In Quito, Ecuador on October 2002, five health workers from Guatemala attended the Latin American Conference on EC organized by LACEC and the Council, where they were trained to implement and follow-up EC activities in their home country. Upon return, the five health workers established the Guatemalan Consortium on EC to coordinate information and training activities on EC. Between February and April 2003, trainers conducted a total of 21 workshops that were attended by 556 participants, including doctors, nurses and social workers, health workers, members of the justice system, female community leaders, and health promoters. Prior to participation in the training workshop, only 14 percent of participants had recommended EC; after training, the percentage increased to 62 .

The Population Council's also provided follow-up technical assistance to activities conducted in Honduras, the Dominican Republic, Mexico, and Paraguay. More than 78 training sessions with over 1,000 diverse participants were implemented. Additionally, a regional program, Youth Encounter, was organized by the LACEC in Nicaragua with over 100 participants from around the LAC region in October 2003, and a meeting addressing reproductive and sexual rights of youth: "A Forum to Think and Make Agreements," was organized by Elige, a Mexican youth network, in January 2004. Lastly, the Council produced and distributed communication materials to service providers and sexual and reproductive health organizations in the region to encourage EC knowledge dissemination and advocacy. As a result of activities conducted under this project, the mass media in Honduras, Paraguay, and Mexico had continuous coverage and discussions on the access and use of EC.

\section{Training of providers of all levels}

The Population Council has expanded the availability of quality EC services for women by training thousands of health professionals in Africa, Asia, and Latin America, increasing their knowledge and awareness of EC and educating them about proper distribution and counseling techniques. Given a general lack of knowledge about EC in many developing countries, even among doctors, training providers is a crucial element for the introduction of EC. A range of providers can be easily trained to educate and provide EC services in the community. Training should be carefully monitored and evaluated, as well as purposefully standardized for consideration of future needs for scaling up nationally. Another method for scale-up includes successfully integrating EC training in to existing training programs for FP. EC training should be organized for all staff in the NGOs and national family planning service delivery systems, including program managers, field supervisors and grassroots workers.

\section{Development of resources}

The Council has developed manuals and handbooks for use by program managers and policy makers in developing countries. One of the two foremost examples is an EC Handbook for policy makers and program managers entitled Introducing and Mainstreaming the Provision of Emergency Contraceptive Pills in Developing Countries, which provides comprehensive guidance for providing EC as a backup for existing contraceptive methods and as a way of preventing unintended pregnancy 
following unprotected sex or method failure. The handbook, aimed at reproductive health program managers and policymakers, presents a step-by-step process for introducing EC that can be adapted to each country's needs and resources. The process, based on research conducted in several developing countries, covers the full continuum of EC programming, including needs assessments and operations research, drug registration, training and logistics, and introduction of EC scale-up.

\section{Advocacy}

In addition to research and technical assistance, the Council collaborates with national and international stakeholders, including advocacy networks, to support the introduction and distribution of EC. The Council's advocacy efforts in this area have led to the expansion of knowledge and awareness about EC in developing countries, an increased demand for EC, and changes in policy.

\section{Information provision, advocacy, and education}

The Population Council has spearheaded information, education, and communication (IEC) programs to promote $\mathrm{EC}$ in a number of developing countries. We have focused on increasing awareness about EC among potential users and providers, correcting misunderstandings and myths, and improving communication between potential users and providers. Council efforts have included mass-media campaigns and the creation of a variety of communication approaches, such as the ECafrique newsletter and a telephone hotline for young people. The Population Council is a founding member of the steering committee of the International Consortium for Emergency Contraception (ICEC) and identifies opportunities to partner with stakeholders. The ICEC is a network of advocates, service providers, pharmaceuticals, and researchers all dedicated to expanding access to EC worldwide, with a focus on developing countries. The Consortium was formed in response to a significant lack of awareness about and access to EC; the network now promotes safe and locally appropriate use of EC within comprehensive family planning and reproductive health services. The Consortium has expanded from its original seven members to include a wide range of organizations, which meet annually and participate in various committees to further the group's mission (http://www.cecinfo.org/).

\section{ECafrique network}

The African Forum on Emergency Contraception, or ECafrique, was established in 2003 under the auspices of the Population Council. A bilingual, international network of health care and business professionals from more than 200 institutions, ECafrique seeks to increase the availability of highquality emergency contraception (EC) services in Africa. The network operates in French and English and functions as a nonpolitical, voluntary association, mindful of Africa's broad ethnic, cultural, and political diversity. ECafrique supports research, advocacy, and service-delivery interventions at the country level, and it disseminates information on improving access to highquality EC services regionally. It publishes a quarterly journal in French and English, the ECafrique Bulletin, covering critical EC issues. Activities also include a publication of the thematic newsletter 
"EC as a Bridge," exploring efforts to link EC users with other methods and services; development of an EC handbook for national programs; production of articles, papers, and country case studies about EC; development of an online database information, education, and communication materials used in Africa (http://www.ecafrique.org/).

The Council provides technical support to ECafrique grantees in East and West Africa through widespread training and sensitization of health providers and users. The Council has developed IEC tools, designed and implemented monitoring and evaluation activities, and has raised awareness among EC communities and policymakers throughout Africa. ECafrique annually awards nine grants ranging from $\$ 25,000$ to $\$ 30,000$ to organizations from across Francophone and Anglophone Africa to increase EC access and to build local capacity to design, implement, and evaluate EC projects. Each grant recipient participates in an intensive proposal-development workshop and receives ongoing technical assistance from ECafrique staff over the life of the project. ECafrique currently operates projects in 11 African countries. The Hewlett Foundation provided initial support for an intensive program of financial and technical assistance to three organizations each in 2007 and 2008. Additional funds from the Compton Foundation enabled the program to double the number of grants it provided in 2007.

\section{Working in Partnerships, Leveraging Funds and Resources}

The Council has been successful in forging strategic partnerships with key national and international stakeholders to introduce, document and scale up EC services. These partnerships have been influential in leveraging not only technical and financial support but in building a base of invested stakeholders, particularly in-country. Generating and sustaining momentum for EC programming has been possible due to the wide coalition of partners.

In particular, substantial financial support has been provided by private foundations (Hewlett Foundation, Compton Foundation) and bilateral (USAID) and multilateral agencies (WHO, UNFPA). Resources provided by private foundations have been instrumental in spearheading research and programmatic activities, as well as leveraging support and resources for innovative program research, which many were hesitant to support. Subsequent bilateral and multilateral donor support has facilitated valuable partnerships and resources to mainstream EC into national programs and ensure its sustainability.

The strategy of cobbling financial resources from a variety of sources has ensured that the flow of resources has remained steady thereby facilitating the generation of evidence and designing of innovative approaches without interruption. More importantly, active interest and engagement of in-country governments has made progress possible. In particular, the Ministries of Health in South Asia-Bangladesh, India, Pakistan and Nepal—have been key in providing our efforts with the legitimacy and sanction required to go to scale and have been willing to share their experiences with other countries in the region. 
Partnering with service delivery organizations such as the International Rescue Committee (IRC), Pathfinder International, and JSI has ensured that state-of-the-art programming knowledge was incorporated from the beginning, and helped develop a variety of different models to suit different contexts. For example, partnering with the IRC facilitated a programming approach most suitable for refugees and other internally displaced populations. The Council is also a member of various professional associations, from which it gains support and assistance.

With multilaterals, in particular UNFPA, we have been able to leverage ability, expertise and incountry presence for the procurement of EC. In countries such as Bangladesh, the procurement of EC through UNFPA has been instrumental in ensuring the sustainability of the program.

\section{Summary}

Since the 1990s, the field of reproductive health and family planning has evolved dramatically. The Council, along with other partners, has contributed to the changes seen in the provision and availability of EC. Emergency contraception is now available in over 140 countries around the world, and in 44 countries EC can be purchased over the counter. Still women's access to EC is far from assured. Efforts continue today to expand access to EC in additional countries and regions and through more integrated contexts, using innovative and effective delivery strategies. For example, the Council is currently expanding its ECafrique program to increase EC availability and awareness in Nigeria. While a lot of progress has been made in the campaign for access to EC, the Council is committed to improving existing methods of service delivery and to leading advocacy efforts and research on EC in new settings and populations. 


\section{References}

Croxatto, H. B., V. Brache, M. Pavez, L. Cochon, M.L. Forcelledo, F. Alvarez, R. Massai, A. Faundes, and A.M. Salvatierra. 2004. "Pituitary-ovarian function following the standard levonorgestrel emergency contraceptive dose or a single $0.75-\mathrm{mg}$ dose given on the days preceding ovulation," Contraception, 70(6) : 442-450.

ECafrique, Population Council. Enquete sur la contraception d'urgence (CU) au niveau des pharmacies. Resume de l'etude.

ECP Handbook: Introducing and Mainstreaming the Provision of Emergency Contraceptive Pills in Developing Countries. The Population Council, Inc. March 2009. Contributors: Hossain, Khan, Vernon, Keesbury, Askew, Townsend, and Rumbold.

Ellertson, Charlotte, Beverly Winikoff, Elizabeth Armstrong, Sharon Camp, and Pramilla Senanayake. 1995. "Expanding access to emergency contraception in developing countries," Studies in Family Planning, 26(5): 251-263.

García, Sandra G, Davida Becker, Marcela Martínez de Castro, Francisco Paz, Claudia Díaz Olavarrieta, and Dolores Acevedo-García. 2008. "Knowledge and opinions of emergency contraceptive pills among female factory workers in Tijuana, Mexico," Studies in Family Planning, 39(3): 199-210.

García, Sandra G, Diana Lara, Sara H. Landis, Eileen A. Yam, and Suyapa Pavón. 2006. "Emergency contraception in Honduras: Knowledge, attitudes, and practice among urban family planning clients," Studies in Family Planning, 37(3): 187-196.

Johansson, Elof, Vivian Brache, Frank Alvarez, Anibal Faundes, Leila Cochon, Sirpa Ranta, Mark Lovern, and Narender Kumar. 2002. "Pharmocokinetic study of different dosing regimens of levonorgestrel for emergency contraception in healthy women," Human Reproduction, 17(6): 14721476.

Keesbury, J. Mainstreaming Emergency Contraception in Ethiopia's Public Sector. Final Project Report. December 2007.

Keesbury J and M Zama. The Copperbelt Model of Integrated Care for Survivors of Rape and Defilement: Testing the Feasibility of Police Provision of Emergency Contraceptive Pills. Population Council Zambia 2009.

Khan, M.E., and Sharif M.I. Hossain. 2008. "Introducing and scaling up delivery of emergency contraceptive pills in the National Family Planning Program of Bangladesh: Enhancing utilization of Operations Research results and lessons learned from program implementation," FRONTIERS Report. Washington, DC: Population Council.

Khan, M.E., Gul Rashida Shaikh, Sharif M.I. Hossain, Ali Mohammad Mir, and Ubaidur Rob. 2008. "Introduction of emergency contraceptive pills in the public health system of Pakistan: A south-tosouth collaboration," FRONTIERS Final Report. Washington, DC: Population Council. 
Khan, M.E., Sharif Mohammed Ismail Hossain and Md. Nizamuddin Bhuiyan. 2005. "Building national capacity to deliver emergency contraception services in Bangladesh," Research Update 3, New Delhi, India: Population Council.

Khan, M.E., Sharif Mohammed Ismail Hossain and Moshiur Rahman. 2004. "Introduction of emergency contraception in Bangladesh: Using operations research for policy decisions," FRONTIERS Final Report, Washington, DC: Population Council.

Kumar, Shiv, Chander Shekher, N. K. Gupta, Malabika Roy, M.E. Khan, Mary Philip Sebastian, Rukma Idnani, Ardash Bhargava, and Vinita Salvi. 2007. "Provision of emergency contraceptive services through paraprofessionals in India," FRONTIERS Final Report, Washington, DC: Population Council.

Muia, Esther, Wilson Liambila, Fariyal Fikree, Joyce Olenja, Lucy Macharia, and Gregory Jagwer. 2002. Emergency contraception operations research project Kakuma Refugee Camp, Kenya: Final Report. Nairobi, Kenya: Population Council.

Muia, Esther, Fariyal F. Fikree, and Joyce Olenja. "Enhancing the use of emergency contraception in a refugee setting: Findings from a baseline survey in Kakuma refugee camps, Kenya." Nairobi: Population Council.

Shreshtha, Mahendra, Sharif M.I, Hossain, and M.E. Khan. 2008. "Strengthening emergency contraception in Nepal," FRONTIERS Final Report, Washington, DC: Population Council.

Westley, Elizabeth and Laura Raney. EC: A Necessary Component of Postabortion FP Services. ICEC/FCI and Population Council.

Yam, Eileen A, Georgina Gordon-Strachan, Garth McIntyre, Horace Fletcher, Sandra G. Garcia, Davida Becker, and Enrique Ezcurra. "Jamaican and Barbadian health care providers' knowledge, attitudes, and practices regarding emergency contraceptive pills," International Family Planning Perspectives, 33(4): 160-167. 